\title{
España y Portugal ante la Segunda Guerra Mundial desde 1939 a 1942
}

\author{
Maria Soledad Gómez de las Heras Hernández
}

Igual que con otros países europeos la España Nacional gestó su amistad con Portugal durante la guerra civil. Si Italia y Alemania eran grandes potencias llamadas a tener un papel estelar en la contienda que se avecinaba, Portugal, por su unidad ideológica con el país vecino, su posición estratégica, y su papel de interlocutor, será también protagonista y estará siempre presente, junto con España, en las relaciones internacionales durante la Segunda Guerra Mundial.

Además de las tensiones que existían entre fascismo y comunismo el asentamiento de un régimen totalitario en España añadía una nueva causa al desequilibrio europeo. Si alguna nación recibió con alivio la noticia del Alzamiento era Portugal: se le brindaba la oportunidad de librarse de la molesta y continua amenaza que suponía el gobierno republicano al otro lado de la frontera. Por otra parte, como la perspectiva internacional admitía la hipótesis de una conflagación mundial, Salazar va a ir configurando su política exterior y encaminándola, ante el conflicto que se aproximaba, a una conservación de la secular amistad con Inglaterra y una postura de neutralidad. A esta neutralidad era necesario arrastrar también a España, esa España a la que, si habia que apoyar frente al peligro comunista, a la vez era necesario no dejarla excesivamente endeudada con los gobiernos totalitarios de derechas.

Había que asegurar en el país vecino un régimen que quisiera y además pudiera ser neutral en la batalla en la que se vería implicada toda Europa. Esa neutralidad no sería posible en el caso de que se consolidara un régimen de izquierdas en el gobierno español, pero tampoco sería viable si, finalizada la guerra civil, España se encuentra endeudada solamente con los totalitarismos de derechas; las consecuencias para llevar a cabo una politica neutral serian semejantes: aliada en uno $u$ otro frente España no podría quedarse alejada de la contienda. Por eso, a parte de 
que Portugal apoya a Franco frente al peligro comunista, una de sus principales batallas diplomáticas va a estar dirigida a neutralizar la influencia nazi en el país vecino.

Dentro del contexto de la política exterior salazarista existía una sola atadura, tan secular como su amistad, que era su vinculación con Gran Bretaña. Cuando los dirigentes españoles de ambos bandos intentan conseguir en Europa el apoyo político, militar y financiero de los paises ideológicamente afines, Lisboa había comenzado tiempo antes las primeras escaramuzas diplomáticas ante el gobierno de Londres. En marzo de 1936 el Ministro de Asuntos Exteriores, Monteiro, en una larga conversación con el Ministro británico pregunta sobre lo que haría el gobierno inglés "cuando las cosas (en España) tomaran mayores proporciones"; Eden se limita a responder que «... esperaba que el gobierno portugués hiciese lo posible por evitar complicaciones... el problema español será un problema más en Europa" '.

Según avanzaba el tiempo se hacia más necesario para el gobierno portugués conocer el talante de Londres ante los inciertos destinos políticos de España y se hace sistemático el acoso de la diplomacia portuguesa a los representantes británicos para que definan su postura ante el abanico de posibilidades que puede presentar el desenlace de la guerra española; es de resaltar la postura huidiza inglesa a dar cualquier respuesta al respecto. En la noche del 11 de junio es el mismo Oliveira Salazar quien solicita un cambio de puntos de vista con el embajador Sir Charles Wingfeld «sobre la implantación en España de cualquier régimen de carácter extremista y comunista... hipótesis que debia interesar también a Inglaterra... nunca se obtuvo del gobierno inglés cualquier respuesta a este respecto. Apenas el Embajador dice en conversación particular al Secretario General que el gobierno inglés no trabaja sobre esta hipótesis. Añadiendo personalmente que el comunismo en España ciertamente desagradaría al gobierno inglés».

Cuando estalla la sublevación española Salazar tenía tomada su decisión. Desde el principio, y antes que otros países, Portugal define una postura de apoyo a los nacionales. Mientras Roma y Berlín conservan aún su actitud de expectativa; Francia se debate entre las simpatías por los gubernamentales y los avisos que recibe de Londres; Rusia no esconde su

Telegrama del Ministro de Negocios Extranjeros, Monteiro, al Secretario General del Ministerio. Londres, 21 de marzo de 1936. Diez Años de Política Externa. V.III. Imprenta Nacional de Lisboa. 1967 
apoyo a las izquierdas, Portugal decide desde el mismo 19 de julio utilizar sus medios políticos y diplomáticos al servicio de la causa nacionalista.

El Ministerio de Exteriores portugués continua en la misma línea de insistencia a Londres para conocer la orientación política de Gran Bretaña en el problema español «... Conferencié con Eden... conté el peligro que corríamos en caso de una victoria de los rojos... me respondió que no podia tomar posición en materia de política interna de otro país. Deplorable salida. Se ve que el conflicto le desagradaba por que tan peligrosa consideraba la victoria de unos como de otros y tanto le desagradaban fascistas como comunistas... Por fin acentuó que el Parlamento no le permitiria la intervención en la política interna de otros países..." Portugal se mantiene firme en su actitud pues, según comunica Monteiro al representante británico, ni puede ser mediador ni, por supuesto, puede permitirse independencia en los asuntos de España "o se da la victoria al ejército nacional o, con la implantación del comunismo en España mi país se vería seriamente amenazado".

Si la Guerra Civil española era el cauce por donde discurría la amistad con la España Nacionalista, también estaba creando la posición más delicada para Portugal que tuvo que hacer equilibrios entre la tradicional alianza con Inglaterra y una perspectiva internacional que le aconsejaba una política de unión con España. En esta estrategia política nunca se sufren tentaciones de abandonar el movimiento de Franco e incluso, en ocasiones, parece que va a anteponerse a la alianza inglesa y romper sus relaciones con Londres.

Una enorme habilidad demostró Salazar cuando, sin alterar su estrategia, intenta una intervención británica más decisiva a favor de la España Nacionalista que pudiera neutralizar la influencia nazi y sobre todo, el endeudamiento de la España franquista con los regímenes totalitarios. Estima el jefe del gobierno portugués que si se efectúa un cambio político en el país vecino y la victoria del partido nacionalista hubiera sido obtenida sólo con la ayuda de alemanes e italianos, obligaría a la Nueva España a una alianza con los paises totalitarios que se volvería contra Gran Bretaña, pues arrastraría a Portugal a la onda Nazi-fascista y la nueva ordenación peninsular significaría la pérdida de la costa Atlántica y Mediterránea. Para evitar estos previsibles peligros el gobierno de Lisboa considera que la actitud de Londres no debe ser de enemistad y antipatía hacia el ejército sublevado «...para no crear en el partido nacionalista un enemigo, basta que su actitud no sea de antipatía para con él en este momento de lucha - si no puede ser de simpatía para quienes combaten contra el comunismo-. En esta hipótesis la gratitud del ejército se iría 
de cierto exclusivamente para los paises que los auxiliasen en el combate..". De esta manera, si el triunfo nacionalista se obtiene sólo con la ayuda de alemanes e italianos, la "nueva España" se vería obligada a una segura alianza que arrastraría a Portugal dentro de la misma órbita y, en definitiva, también perjudicaría a Inglaterra?

En el año 37 cuando, dentro del panorama europeo, Rusia está resultando peligrosa a los intereses británicos, Gran Bretaña deseaba empezar a entenderse con los nacionalistas, posibles vencedores, el Comité de No Intervención se exhibía como un rotundo fracaso y la postura de las potencias europeas con respecto a las partes beligerantes estaba claramente definida en favor o en contra de cada uno de los dos bandos, Portugal cesa, momentáneamente, su política entre bastidores en favor de la España Nacional. Ante la nueva reorganización de la política internacional presidida por el interés de Europa en la aceleración de la guerra española, las autoridades portuguesas consideran que ha llegado el momento de enviar un representante al gobierno de Burgos -diciembre de 1937-proceso de aproximación que se verá reforzado por el reconocimiento oficial en mayo de 1938.

A la altura del verano de 1938, cuando el motor del desequilibrio europeo no era ya la guerra civil española sino el conflicto que se avecinaba, Franco se ve dentro de unas coordenadas internacionales cada vez más comprometidas. Alemania, que ya en marzo se había enexionado Austria, anunció su intención de ocupar Checoslovaquia en la primera ocasión que se le presentara. A partir de este momento la cuestión checa, que fue a la vez el primer plano y el telón de fondo de toda la política exterior, estuvo a punto de desencadenar la Segunda Guerra Mundial. España, ante la posibilidad de verse involucrado en un conflicto de ámbito europeo, amenazadas la frontera de los Pirineos y el Marruecos español ,viró hacia una política de buenas relaciones con Inglaterra y un aparente distanciamiento de Alemania e Italia. Por ello, se tuvo mucho cuidado en no entrar en ningún pacto militar con Hitler y sólo se acabó firmando entre España y Alemania un tratado de amistad no demasiado comprometedor. Mientras el Führer, interesado en atraer a España a una negociación que permitiese utilizar el terreno peninsular y obtener importantes concesiones mineras, utilizaba la ayuda material de la Legión Cóndor como medio de presión, disminuyendo o aumentando los envíos, Franco esquivó cualquier

2 Conversación entre Monteiro y Doz mantenida el 7 de agosto de 1936. Recogida en Diez Años de Politica Externa. Vol II. Lisboa, Imprenta Nacional, 1974. 
compromiso bélico y ofreció en las inversiones de minerales participaciones escasas y poco rentables. Con respecto a Italia, la política española fue similar. Cuando Mussolini, ante el desgaste de las fuerzas italianas, propuso la doble alternativa de evacuar tropas o de enviar a la Península nuevos soldados, Franco, aún enzarzado en la batalla del Ebro, optó sin dudarlo por la primera opción: no quería más voluntarios extranjeros.

La idea de una conflagación entre las potencias europeas, no era ni beneficiosa ni tranquilizadora para los franquistas: por un lado, en su territorio todavía luchaban combatientes italianos y alemanes, circunstancia que no favorecia su postura neutral, por otro, de las dos fronteras con los paises vecinos, la del norte, que lindaba con un pais políticamente contrario, resultaba amenazador. Era, por tanto, necesario asegurarse que no venía ningún peligro por la otra frontera y se estrechan lazos de amistad con Portugal. Esta nación era aliada de Gran Bretaña, había prestado ayuda en y durante el Alzamiento, doctrinalmente Salazar era cercano a Franco, sólo faltaba concretar que postura adoptarian los dos países ibéricos ante el previsible conflicto en el Viejo Continente. La aceleración de los sucesos en el escenario europeo, creando una situación internacional de extrema tensión, facilitaron que estas naciones peninsulares hicieran mutuas declaraciones de neutralidad.

Si el Quai d'Orsay comunicó al representante oficioso nacionalista, Quiñones de León, que si llegaba a producirse un enfrentamiento con Alemania, los ejércitos franceses invadirían Cataluña y el Protectorado de marruecos, el Foreing Office llamaba a Alba para advertirle que, efectivamente, Francia optaría por esta invasión si España no se declaraba neutral. El General Franco confirmó su incondicional neutralidad. Esta decisión no solamente fue determinada por el requirimiento francés, Inglaterra tenía urgencia por conocer la postura de los previsibles vencedores de la contienda española y los nacionales necesitaban mantener tranquila a la opinión política inglesa y francesa para concluir la guerra. Tras estos concluyentes motivos, entre bastidores, Portugal acercaba a España hacia la opción neutral: «Portugal - diría Salazar en su discurso de 27 de octubre - se encontraria en una difícil situación si por política española o internacional hubiera tenido que combatir contra el país vecino y haberse visto en la necesidad de contribuir a la destrucción de lo que con tanta simpatía hemos visto edificado... lo más conveniente es que España se mantuviese neutral ante cualquier conflicto que estuviese relacionado con Europa Central y hay que tratar de ayudar a sus gobernantes a mantenerlo».

Los compromisos de Munich, en donde Daladier y Chamberlain comunicaron la esperada decisión de Franco, esta postura nacionalista ante los 
posibles acontecimientos europeos, el reconocimiento por parte de Francia e Inglaterra de la "Nueva España» y la momentánea paz en Europa, abrió una nueva etapa en la política exterior de la España franquista presidida por una mayor unión con Portugal.

En marzo de 1939 se firma el tratado de No-Agresión ${ }^{3}$ que había surgido, por iniciativa de la diplomacia española, en julio de 1938 como fórmula de "buena vecindad" y tras un intercambio de pareceres, fue aprobado, con cierta prisa y previa consulta a Londres, por Salazar en febrero de 1939. Oficialmente Jordana da instrucciones a la prensa sobre su publicación: "Acompaño a usted dos notas para la prensa concerniente al Tratado de Amistad y No Agresión que hoy se firma en Lisboa entre España y Portugal. La nota breve debe ser publicada en la prensa de mañana, sin comentarios, pero destacando en grandes titulares la noticia a fin de dar el debido realce a este acontecimiento; la más extensa en que ya se detalla el contenido del acuerdo debe aparecer pasado mañana día 19, que es cuando deben hacerse los comentarios con máxima extensión y en lugar importante cual corresponde a la calidad del asunto y a la inmejorable amistad de los dos países". En las coordenadas internacionales este pacto permitía al gobierno portugués mantener libremente su alianza con Inglaterra, alejaba todo recelo sobre la actitud española y a España le aseguraba no tener ninguna amenaza por la frontera portuguesa y, sobre todo, presentaba a la Península lbérica ante la Segunda Guerra Mundial ideológicamente unida y políticamente neutral.

Si Salazar ve como suya la victoria de la España Nacional ${ }^{4}$ así lo consideraba también un aliado de Franco mucho más generoso, Mussolini; esta amistad hispano-italiana, nacida con el conflicto bélico español y que se consolidaría en el período inmediato de la posguerra ${ }^{5}$ fue un factor que desequilibraría la hábil política salazarista trazada respecto a España. Los cinco meses que transcurrieron entre el final de la guerra civil y el estallido de la Guerra Mundial, momentos llenos de incógnitas para toda Europa, no suponen una fórmula diplomática precisa en la relación entre los dos países ibéricos.

Gomez de las Heras Hernández, M.S. El pacto de No-Agresión hispano-portugués de 1939. Historia $16, \mathrm{n}^{\circ} 130$, págs $11-18$.

${ }^{4}$ "... En todos los dominios en que era libre nuestra acción, ayudamos en lo que pudimos al nacionalismo español...enfrentados por todas partes a la incomprensión y a la ceguera de Europa, donde la España nacional tan pocas amistades contaba, fuimos desde la primera hora lo que debimos ser : amigos fieles de España, en el fondo peninsulares. Perdimos vidas, corrimos riesgos, compartimos sufrimientos, y no tenemos cuentas que presentar. Vencimos, es todo." Discurso de Salazar ante la Asamblea Nacional el 22 de mayo de 1939.

5 Ver Tusell, J y Garcia Queipo de Llano, G. Franco y Mussolini Madrid. Ed. Planeta, 1985. 
La vinculación especialmente estrecha de Franco e Italia y una situación internacional que favorecia y propiciaba frecuentes especulaciones más o menos infundadas ${ }^{6}$, crearon grandes inquietudes en Lisboa. El temor de Portugal a una España entroncada de lleno en la órbita del Eje es la preocupación constante y común que predomina en la documentación diplomática de este período: «... no creo que España haya cambiado de ideas ni admito que vaya a cambiar en breve... ni la posibilidad de un entendimiento oscuro con Alemania e Italia para hacernos un golpe a la manera de Albania. Esto es completamente inverosímil, por lo menos por ahora... El embajador inglés no admite la hipótesis de un ataque a Gibraltar a la "alemana". Solo en caso de guerra generalizada sería viable... No obstante persiste un peligro muy grave: la guerra. Si hay guerra España va a pasar un mal momento y corre el riesgo de verse arrastrada hacia los otros..."?

La actitud de la diplomacia portuguesa es de máxima prudencia para no mostrar desconfianza hacia España «... telefonee al General Jordana... no mostré prisa para no darles la menor impresión de alarma... es indispensable que no demos a España la menor idea de desconfianza o de recelo... en la conversación que tuve con el General Jordana tuve el mayor cuidado en decir todo lo que era preciso y hacer todas las advertencias, sin dar nunca esa impresión. Cuando aludí a los rumores, fueron siempre los rumores que tendian a sabotear el pacto de amistad: quedaba pues España avisada para neutralizar las manifestaciones que pudiesen llevar a suponer que había cualquier desconfianza entre nosotros...". Al otro lado de la frontera, España llevaba a cabo una política que, si no favorecía los recelos portugueses, al menos los justificaba. En la cúpula del Estado se agitaba un núcleo favorable a Alemania y en el gobierno un papel creciente lo desempeñaba Serrano Súñer que tan decisivo era para alemanes e italianos como poco favorable para Portugal; Serrano partia para Italia en el momento álgido del empeoramiento de las relaciones hispano francesas, los ataques en la prensa, controlada por él, contra Inglaterra y sobre todo Francia son cada vez mayores ${ }^{8}$; por otra parte, la caida de Jordana, mucho más prudente y deseoso de no malquistarse con nadie,

6 Por este tiempo corrian en los medios diplomáticos de Lisboa rumores acerca de una inminente invasión de Portugal por las tropas italianas. El 17 de abril era divulgada una nota oficiosa conteniendo un desmentido del gobierno italiano

Correspondencia de Teotónio Pereira a Salazar. 19 de abril de 1939.

s Serrano Suñer durante su viaje a italia comenta a Ciano que «en bien de la propia España y del Eje se debia llevar a cabo una acción que provocara la desvinculación de Portugal e Inglaterra para lo que se requeria la colaboración italiana". 
coincide con un distanciamiento de las potencias democráticas. Por parte de Franco, la necesidad de congraciarse con «los amigos" de Salazar fue coyuntural, había terminado con la guerra civil e incluso antes, con el reconocimiento internacional de la España Nacional y, de momento, el acercamiento al país vecino se hacía menos perentorio; el Generalísimo que nos presenta la correspondencia diplomática portuguesa responde a un hombre «bastante perturbado por las grandezas del mando, enamorado del poder personal, deslumbrado por el poder y las ideas del Eje... ${ }^{9}$ actitud que frecuentemente exasperan al embajador portugués y no facilitan una estrechas relaciones diplomáticas entre Burgos y Lisboa.

A pesar de las fobias políticas del ministro español y la inclinación amistosa de Franco hacia Italia, el Jefe del Estado Español presenta, en la entrevista oficial que le fue concedida al diplomático Augusto de Castro ${ }^{10}$, un talante conciliador: "no creo en la guerra - afirma Franco- me niego a creer en la guerra. No veo cuestión en el mundo que no pueda ser resuelta por los medios diplomáticos y pacíficos". Ante la comprometida situación en que se encuentra Europa, y aunque es el deseo de España colaborar en la consecución de la paz, si fuera inevitable el conflicto ${ }^{11}$ Franco se reafirma en la necesidad de la neutralidad. En las relaciones internacionales europeas, aboga por un bloque ideológico en el que se encontrasen Portugal, España e Italia con la bendición, eso sí, de Gran Bretaña ${ }^{12}$. Con una clara referencia a la política de España respecto al Eje y su posible influencia para evitar la guerra ${ }^{13}$ concluye la entrevista ${ }^{14}$.

El desconcierto sobre la orientación política española, en unos momentos en que las relaciones hispano-italianas están marcadas por una especial intimidad, le conduce al diplomático y periodista luso a recordar la valiosa

9 Correspondencia de Pedro Teotónio Pereira y Salazar, 11 de julio y 28 de agosto de 1936.

10. Augusto de Castro fue diplomático en Londres, en El Vaticano y en Bruselas. Fué embajador en Paris y director del Diario de Noticias.

11 "Bélgica -dice Franco en 1914 no deseaba la lucha y le fue impuesta. De esta forma, España, segura de su fuerza y del valor de sus hijos, no desea la guerra, pero no la duda".

12 "... la politica británica no es, ni puede ser, sino una política geográfica. Bajo el aspecto de los graves intereses de su politica geográfica, déjeme decirle que si Gran Bretaña encontrase unidos en un mismo campo ideológico de amistad y afecto. Portugal. España e Italia, la politica inglesa no tendría sino que bendecir este hecho, a Gran Bretaña le permitiria, además, ser amiga de todos».

"Cree, Excelencia, que por su posición y por un conjunto de circunstancias, España en este momento puede por su actitud y su politica, ejercer una acción internacional con influencia decisiva en el aplazamiento y posiblemente en la propia forma de evitar la guerra". - No creofue la contestación de Franco.

14 Entrevista publicada en el Diario de Noticias de Lisboa el 18 de julio de 1939, de la que la prensa española no hizo alusión. 
ayuda recibida por los nacionales desde Portugal durante la guerra civil y sondear el grado de agradecimiento de Franco con preguntas, inconvenientes y ausentes de todo tacto, pasadas al Generalísimo en unas primeras notas de respuestas ${ }^{15}$; no sólo provocaron enorme malestar al entrevistado sino también gran inquietud en los diplomáticos portugueses que se mantenian en una política de "cautela", aunque llena de recelos, hacia España: «al Generalísimo no le debe haber gustado y respondió mal en muchos puntos... Sé que salió alarmado de ciertas cosas que escuchó del Generalísimo. No debe en el resto de haber dicho cosas nuevas de lo que oí en mayo en la última conversación... 16 «... lo mejor había sido evitar el incidente... de sobra sabemos nosotros lo que piensa el Generalísimo y los peligros de ciertas ideas que le acechan y no me tiene engañado. Esta gente es lo que siempre fue. No conviene darles ocasión de que se volvieran contra nosotros..." "17. La actitud de precaución era recíproca entre los dos paises ibéri$\cos$ y no hay referencia de respuesta alguna por parte de España ${ }^{18}$.

Desde la última semana de agosto los acontecimientos se precipitaron hasta llegar al conocido desenlace. Cuando estalla la Guerra Mundial los dos países ibéricos se declaran, como era previsible, neutrales, pero uno y otro difieren sustancialmente en la naturaleza de su neutralidad: mientras la aprobación a Portugal se la da Inglaterra, a Franco el visto bueno se lo comunica Mussolini ${ }^{19}$. El que cada una de las dos naciones estuviera enmarcada en campos opuestos, les permite a estos paises de segundo orden alzarse como interlocutores privilegiados y asumir el papel de intermediarios en asuntos que no podian ser abordados por las grandes potencias ${ }^{20}$.

\footnotetext{
15 ¿Que piensa V.E. de la cooperación de Portugal en los primeros tiempos? Portugal fue muy simpático, pero la verdad es que salvó la piel pues sabia bién lo que podía esperar de los rojos.

¿Sabe que hubo 6.000 portugueses muertos en la guerra?. No se el número, pero mandé hacer un sumario y después diré cuantos murieron.

¿Que piensa del Tratado de Amistad y No Agresión? Muy bueno

16 Correspondencia entre Pedro Teotónio Pereira y Salazar, 4 de agosto de 1939. Idem 11 de agosto de 1939.

18 Solamente Jordana preguntaria al Embajador Portugués « ¿De verdad ese hombre ha sido diplomático? ¿Ocupó los cargos que dice? - Yo respondi como pude- comentó Teotónio Pereira a Salazar.

19 "Deseo decirle inmediatamente que apruebo plenamente su declaración oficial de neutralidad y creo que podrá conservarla hasta el final de la guerra", Mussolini a Franco, 6 de septiembre. Cita tomada de Tusell. J. ops. cit., pág. 49.

20 Bonnet,que procuró desde el primer momento que no estallara la guerra, solicita a Franco, dada su vinvulación con el Eje, que se dirija a las potencias interesadas en el conflicto en un intento de evitar la guerra. Portugal es un interlocutor privilegiado ante el gobierno británico e incluso, a veces de Francia, que solicita de Portugal que intervenga ante España pues " está en situación especialisima para conseguir detenerla en dirección del Eje".
} 
Los derroteros por donde se fue deslizando la contradictoria política española, por un lado su aproximación al Eje mientras por otro se reafirmaba en las garantias de neutralidad tendidas a los aliados vía Portugal, las tentaciones intervencionistas y sobre todo, el telón de fondo de una política interior con la preeminencia, cada vez más fuerte, en la cúpula del Estado Español de un núcleo favorable a Alemania ${ }^{21}$, obligan a España a una politica de equilibrios con la que no se estrechaban lazos con Portugal. El Pacto Germano-Soviético sería la única grieta por donde Portugal intentaría debilitar las relaciones de la España de Franco con el Eje; este pacto venía a constituir — según Portugal- la prueba real de la total ausencia de la comunidad ideológica de los respectivos paises con Alemania «... esta vez que no vengan a hablar de cruzada ideológica los que agitan la bandera de los soviets".

Los meses desde el estallido del conflicto y la entrada de Italia en la guerra, Franco se mantiene en las coordenadas de la política internacional de los últimos tiempos, con una posición favorable a Alemania y dentro de la órbita italiana. Los acontecimientos que se van sucediendo en el escenario internacional empujan a España, donde no está ausente la desorientación, a una actitud cada vez más incomprensible para el país vecino. ${ }^{22}$. Las relaciones con Portugal se podrían definir como incontrolables. Con la guerra en Europa la cuestión española se disloca hacia un plano que está ya por encima de las fuerzas de la diplomacia y todo depende ya de factores con los que poco o nada pueden hacer. La sensación de impotencia del embajador en España le lleva a pedir su relevo: " Voy a pedir a V.EX ya, a parte de otras razones, siento que ya nada puedo hacer una vez que la guerra se ha metido en unos engranajes superiores a nuestras fuerzas. $Y$ ya no hablo de la poca habilidad que siento para esta carrera y del esfuerzo que he tenido que hacer para suplir las cualidades que no poseo" ${ }^{23}$.

\footnotetext{
Petain le habia preguntado a Serrano Suñer cual seria la actitud de España en los meses de guerra futuros y escuchó la respuesta de que "España seria tan sinceramente no intervencionista como lo fue Francia durante la Guerra Civil española". Aunque fue una amenaza verbal. se le consideraba lo suficientemente francófobo como para desear la guerra al lado de Alemania.

Con motivo de los titulares «Ucrania y la Rusia Blanca normalizadas» en una prensa, como es conocido, controlada por Serrano Suñer, le pregunta el embajador portugués al ministro español, a cerca de si esa normalización era la ocupación por los métodos soviéticos: la misma normalización que reinaba en Madrid, Barcelona, Alicante durante la ocupación roja; la normalidad de la vida que tuvo en la cárcel durante casi dos años y le mataron dos hermanos. ¿Parece que nos equivocamos, que no era Rusia? - Era también Francia-contestó Serrano Suñer.

La primera vez que Teotónio Pereira le pide la sustitución a Salazar es el 22 de septiembre de 1939, despues serán sucesivas las veces que insistirá alegando diversos motivos, hasta que se enderezan las buenas relaciones con España.
} 
Antes de junio de 1940 no era ningún secreto para los diplomáticos portugueses ${ }^{24}$ la intención de Italia de participar en las hostilidades. De la cadena de acontecimientos que sucederían a la entrada de Mussolini en el conflicto el mayor temor lo infundia la posibilidad de que España se viera arrastrada a la guerra. En tan delicada situación, y aunque las presiones a Franco para que participe al lado de los alemanes están alarmando al embajador ${ }^{25}$, Salazar intenta mantener intacto el clima de confianza y de lealtad hacia el Generalísimo "estoy convencido de que el Generalísimo trabaja por la neutralidad sinceramente... conviene ir preparando todas las maniobras desde el principio y colaborar con el Generalísimo en el sentido de la defensa común, no dejando que envenenen la atmósfera con la existencia de sentimientos hostiles de Inglaterra en relación a España, que ella favorece, por que los enemigos de ahora ya le bastan» ${ }^{26}$. Franco parecía ajeno a los buenos propósitos portugueses, deslumbrado por las victorias alemanas, estaba seguro de que la guerra sería corta; aunque en estos momentos no deseaba ni podía participar en la contienda de un modo activo, tenía la convicción de que Hitler ganaría la guerra y, mientras mantenia en el horizonte las esperanzas de las reivindicaciones territoriales, deseaba estar próximo al Eje para unirse al carro de la victoria en el momento oportuno. Serrano Suñer, también convencido que "la guerra acabaría en tres semanas o en un mes" sentía un cierto alivio al suponer finalizada la hegemonía británica y sustituida por la germánica. Respecto al sentir general de su país vecino el Embajador portugués lo presenta como seducido por los aparentemente vencedores en Europa: «Fuera de duda España continua odiando a los aliados. Pocas son las personas que consiguen elevarse por encima de este resentimiento. Las victorias alemanas son recibidas con júbilo... Infelizmente las cosas están corriendo de tal manera que no es difícil convencerlos de que Alemania no va a ganar la guerra... Los más razonables cuando se les habla de las ventajas de la neutralidad, mascullan siempre: si, de hecho no podemos hacer la guerra,

\footnotetext{
Teotónio Pereira le escribe a Salazar el 14 de abril «Vengo de visitar al Mariscal Petain. Cree que Italia va a entrar en la guerra" y el 6 de mayo, con gran preocupación sobre el mismo motivo comunica «vengo de despedirme del Almirante Estrada y dice que tiene como cierta la entrada de Italia en la guerra" Correspondencia de Pedro Teotonio Pereira para Oliveira Salazar. Vol. 11.

25 "Tengo una cosa grave que comunicar a $V . E^{a} \ldots$ Se de fuente segura que ayer por la tarde fue hecha una diligencia muy seria a España para forzarla a ir a la guerra al lado de los alemanes. Llegó a ser propuesta - según me aseguran- la movilización general. Franco resistió en no ceder". Teotónio Pereira a Salazar 10 de mayo de 1940.

26 Carta personal de Salazar tranquilizando a su Embajador en España de 12 de mayo de 1940. Está publicada en la Correspondencia de Teotonio Pereira y Salazar. Vol. Il.
} 
estamos mal preparados. Quiere decir: no es que juzguen la guerra infame; es que se creen en mala posición para intentar el golpe. Si V.EXci ${ }^{\underline{a}}$ me pregunta cuáles son los que sienten los peligros de la hegemonía alemana, le diré que son más raros que un trébol de cuatro hojas. En este aspecto el instinto de salvación, la fé católica, el espíritu latino, son apagados por el odio contra Francia y contra Inglaterra» ${ }^{27}$.

Como ya esperaban los círculos diplomáticos europeos Mussolini lanza a la guerra a Italia al lado de Alemania y los combates se extienden al Mediterráneo ${ }^{28}$. Era el afán del Duce extender las posesiones italianas en la cuenca occidental del Mediterráneo y Tánger, Marruecos, Gibraltar y las Baleares son blancos potenciales; Beigbeder conoce las intenciones italianas, las Baleares interesan como bases avanzadas y la ayuda italiana en la guerra civil no ha estado exenta de un proselitismo Mediterráneo; sobre todo la perspectiva de la intrusión italiana podía llevar a la guerra en un mal momento. España, trabada en su neutralidad, se declara el 12 de junio no-beligerante.

Esta declaración de no-peligerancia no había sido dado a conocer previamente a Salazar "creo que en la carta que escribí a V.Ex $x^{\circ}$ dije claramente lo que fue la conversación con el Generalísimo. No hay duda que ayer en la reunión cambió de parecer y fue para la no beligerancia. Triunfo de Serrano y de las ideas que él ha exteriorizado... tuve una larga conversación con el General Varela... le expliqué el caso de la no-beligerancia. Veo que no tenía idea exacta del asunto y que fue llevado por los otros". El Gobierno Español hace saber a Lisboa, por medio de Nicolás Franco, que la actitud adoptada frente a la guerra no comporta el más pequeño desvío de la neutralidad.

La tentación belicista de España produce la mayor inquietud en los medios diplomáticos británicos y portugueses, ambos comparten la posibilidad de ver a España entrar en guerra de un momento a otro ${ }^{29}$. El margen de

Telegrama de Teotónio Pereira a Salazar de 27 de mayo de 1940

28 "Por paradójico que pueda aparecer, el hecho más importante de este frente que se abre en el sur va a producirse entre la España franquista y la Italia fascista. No en forma de un enfrentamiento militar sino de una carrera de velocidad entre las "hermanas latinas". SEGUELA. M. Franco -Petain. Los secretos de una alianza. Ed. Prensa Ibérica, S.A. Barcelona, 1994, pág.77.

29 He ido a ver a Beigbeder... debo confesar que he pasado unas horas de mayor ansiedad - le comentó Hoare a Teotónio Pereira - "Creo que el mayor cuidado de Hoare residía en la posibilidad de ver a España entrar en la guerra de un momento a otro, a la manera italiana. Yo le aseguré que juzgaba eso imposible por lo menos mientras Franco mandase en España... Pero temo mucho que los alemanes y los italianos ejerzan aqui una presión brutal y lleven a Eśpaña a lanzarse a la guerra". Telegrama de Teotonio Pereira a Salazar, 20 de junio de 1940. 
maniobra que tenía el gobierno de Salazar y la misma Gran Bretaña para aliviar la presión que ejercia el Eje sobre la Península era muy corto. Se hizo necesario crear un procedimiento que ligara al gobierno español a la neutralidad y este fue la política de auxilio económico que Inglaterra realizó a través de Portugal quedando ella en la sombra ${ }^{30}$.

Si la evolución del escenario europeo contribuyó de manera decisiva al distanciamiento diplomático con Portugal sería también la evolución de este mismo escenario quién volveria a facilitar y presenciar la amistad peninsular. España, que a pesar de sus alianzas sigue condicionando sus compromisos de entrar en la guerra cuando le fueran dados los apoyos económicos y militares necesarios y sus reivindicaciones territoriales, sigue una política cautelosa hacia el país vecino. Una interrelación de factores de política interior y exterior crean una atmósfera favorable a un acercamiento a Portugal: las presiones sobre España cada vez con más fuerza de los bloques enfrentados - unos para que entrara en el conflicto y otros para que mantuviera su neutralidad - y sobre todo el sustrato de penuria económica, propician un intento de recuperar la debilitada amistad con el pais vecino.

Nuevamente, como en el tratado de Amistad, España ve amenazadas sus fronteras y ve la necesidad de estrechar relaciones con Portugal; con las tropas alemanas en la frontera de Irún, si Portugal entrara a formar parte en el conflicto, Alemania podria exigir el paso por España para alcanzar la otra nación peninsular. Para Serrano la alianza con Inglaterra constituía un peligro, pues podría ser utilizada como pretexto por los alemanes para invadir la Península. Sería, por ello, el mismo Serrano Suñer, quién alegando lo comprometido de las circunstancias europeas, propicia un alejamiento de Portugal de la alianza británica a cambio de una unión más estrecha con España mediante un tratado más amplio incluso de carácter militar. La materialización del nuevo anudamiento entre los dos países ibéricos fue la firma del Protocolo Adicional que volvía a tener como interlocutor a Nicolás Franco y Salazar desde Lisboa y a Franco y Biegbeder en Madrid. La repercusión en Europa del nuevo acuerdo Peninsular fué, según la correspondencia diplomática, felizmente aceptada "Acerca del Protocolo - diría Teotonio Pereira a Salazar - se dice encantado. Todos se mostraban satisfechos, los ingleses y los del Eje, a cada cual explicaba el caso a su manera. Franco estaba muy contento con el efecto obtenido tanto externa como internamente". Ciertamente en el

30 Acuerdos comerciales. M.A.E. leg. 2.075. exp.8. 
marco de las complicadas relaciones internacionales se recibió la noticia del Protocolo Adicional según lo que a cada beligerante le interesaba interpretar; los ingleses, que estuvieron al tanto de todas las negociaciones, lo entendieron como un nuevo reforzamiento de la alianza peninsular para mantener la neutralidad de España y Portugal frente a las presiones del Eje; Alemania e Italia quisieron creer que la renovación de la unidad peninsular se debía a una atracción de Portugal hacia la órbita de la política exterior española, con lo que ello suponía de un cierto alejamiento de Gran Bretaña ${ }^{31}$.

Hitler tenia una visión muy realista de la situación de Portugal y nunca esperó que pudiera separarse de Inglaterra, pues, entre otros motivos, vería sus islas ocupadas; era inútil ejercer presiones diplomáticas sobre Lisboa. Es posible que Serrano Suñer, que no tuvo oportunidad de intervenir en la negociación, pensara en la remota posibilidad de una ruptura de la secular alianza de Portugal con Inglaterra, lo cierto es que esta desvinculación no se produjo, por el contrario, el reforzamiento de la alianza peninsular mantenia y fortalecía la buscada neutralidad de la Peninsula Ibérica frente las presiones del Eje y respaldaba la imperiosa necesidad de España de mantenerse alejada del conflicto. Era un triunfo para la política buscada por Londres desde que se preveía el conflicto mundial, y del mismo Salazar que habia impedido una mediatización como la intentada originariamente por Serrano Suñer.

La debilidad económica española que tiene como única salida conseguir los suministros básicos procedentes de los aliados o negociar el control marítimo que ellos habian creado; la consiguiente presión británica sobre los abastecimientos, pues España depende estrechamente de su importación y sólo recibe del extranjero lo que deja pasar el bloqueo inglés, saben que España recibe mucho por mar y no puede vivir sin las importaciones de artículos de primera necesidad y los convenios comerciales, en los que actuó como intermediario Portugal, hacen que Franco se vea nuevamente dentro del ámbito anglo-portugués. La insistencia Alemana fue cediendo en favor de nuevos planes militares que ya no se ocupaban de la zona occidental, sino de la invasión de Rusia.

A la actitud marcadamente "pro-Eje" de España, Salazar adoptó una política benevolente. Aunque el nombramiento de Serrano Suñer como Ministro de Asuntos Exteriores hace que las relaciones diplomáticas

31 Gomez de las Heras. M.S. y Sacristán, E. «España y Portugal durante la Segunda Guerra Mundial». Espacio, Tiempo y Forma. Serie V, № 2, pág. 209-225. 
aparezcan más debilitadas ${ }^{32}$, y que jamás se le informa previamente de los encuentros mantenidos entre España y los paises del Eje, Salazar sabe que Franco no va a entrar en guerra; piensa que los intervencionistas son ese núcleo que se encuentra en la cúpula del Estado y que, además, según dice el embajador portugués "Serrano es un histérico convencido de que los alemanes lo tomarían en serio en caso de una victoria.. los falangistas están felizmente divididos" y si hay alguien que frena esas tentaciones intervencionistas es precisamente el mismo Franco y, por encima de todo ello, no está dispuesto a alterar sus relaciones cordiales con España y le conviene aceptar su voluntad neutralista. Los acontecimientos que se siguieron produciendo en Europa marcaron los nuevos cauces de la politica bilateral peninsular que desembocaron en el Bloque Ibérico ${ }^{33}$.

\section{FONDOS DOCUMENTALES:}

A.M.A.E. de Madrid. Leg. 1050; Leg. 1051; Leg. 2.070

A.M.A.E. de Lisboa. leg. 101; Leg. 111; Leg. 10.

32 La prensa que sigue controlando Serrano Suñer contiene ataques que llevan a la situación de que se prohiban vender periódicos españoles en Portugal.

33 Gomez de las Heras,S. y Sacristan E. Ops. cit., págs. 218-225. 